\title{
Natural fibre selection for composite eco-design
}

\section{Corona, Andrea; Madsen, Bo; Hauschild, Michael Zwicky; Birkved, Morten}

\section{Published in:}

C I R P Annals

Link to article, DOI:

10.1016/j.cirp.2016.04.032

Publication date:

2016

Document Version

Peer reviewed version

Link back to DTU Orbit

Citation $(A P A)$ :

Corona, A., Madsen, B., Hauschild, M. Z., \& Birkved, M. (2016). Natural fibre selection for composite eco-design. C I R P Annals, 65(1), 13-16. https://doi.org/10.1016/j.cirp.2016.04.032

\section{General rights}

Copyright and moral rights for the publications made accessible in the public portal are retained by the authors and/or other copyright owners and it is a condition of accessing publications that users recognise and abide by the legal requirements associated with these rights.

- Users may download and print one copy of any publication from the public portal for the purpose of private study or research.

- You may not further distribute the material or use it for any profit-making activity or commercial gain

- You may freely distribute the URL identifying the publication in the public portal

If you believe that this document breaches copyright please contact us providing details, and we will remove access to the work immediately and investigate your claim 


\title{
Natural fibre selection for composite Eco-design
}

\author{
Andrea Corona ${ }^{a}{ }^{*}, B$ Bo Madsen ${ }^{b}$, Michael Zwicky Hauschild ${ }^{a}(1)$, Morten Birkved $^{a}$, \\ ${ }^{a}$ Quantitative Sustainability Assessment, Department of Management Engineering, Technical University of Denmark, Lyngby, Denmark \\ ${ }^{b}$ Composites and Materials Mechanics, Department of Wind Energy, Technical University of Denmark, Roskilde, Denmark \\ *Corresponding author. Email address: corona@dtu.dk
}

\begin{abstract}
Natural fibre composites (NFC) are gaining interest in manufacturing because they address some of the environmental problems of traditional composites: use of non-renewable resources, and large impacts related to their production and disposal. Since natural fibres are not yet optimized for composite production, it is crucial to identify the most appropriate applications, and determine the optimal fibre/matrix ratio. A methodology is proposed for early-stage decisions support on selection of bio-composite materials. Results help identify the application with the largest reduction in environmental burden and show that the fibre/matrix combination with the lowest environmental burden also has the best mechanical properties
\end{abstract}

Lifecycle; Composite; Eco-design Methodology

\section{Introduction}

Composites offer high mechanical stiffness at low material density. This combination of properties makes them attractive for use in lightweight constructions. When used in a dynamic application (e.g. in a car), the weight reduction offered by composite materials may allow considerable fuel savings. On the other side, the production and disposal of conventional composites based on glass or carbon fibre is related with considerable environmental and human health challenges [1]: the fibre production process is energy intensive, while the heterogeneity of composite materials creates problems with their disposal.

Use of plant fibres in composites can help overcome some of these difficulties. They can be produced from a renewable and almost carbon neutral feedstock, the energy consumption for their production is moderate and their disposal causes fewer environmental issues, since the fibre are biodegradable or when incinerated they can produce energy [2]. However, the use of natural fibres (NF) for composite production has not yet been optimized to achieve the highest mechanical properties and to identify the best applications.

Life Cycle Assessment (LCA) is the tool of choice for assessment of the environmental performance of a product or service. Previous LCA studies of natural fibre composites (NFC) are limited. Comparative studies have been based on mass-to-mass comparisons ignoring differences in stiffness between the compared materials [3]. Alternatively, they have resorted to use of simplified micromechanical models for calculating the mechanical properties of the composites [4], not suitable to represent the behaviour of natural fibre composites due to their special characteristics compared to synthetic fibre composites, as pointed out in [5]. An important problem related to use of $\mathrm{NF}$ is the typically higher porosity and the lower maximum obtainable fibre volume content of the resulting composites compared to the use of man-made fibres [5].

In addition, LCAs of various products based on NFC indicate that the type and context of the application of NFCs influences the outcome of the comparison with conventional fibres.

In order to evaluate such materials properly, an adequate framework is needed, which accounts for all those issues and is generalizable to assess all composite type.

This paper proposes an assessment framework that addresses these shortcomings. It caters to the needs of Life Cycle Engineering (LCE) by taking into account specific (mechanical) properties of the material as well as the application context of the material in order to develop a more relevant life cycle inventory (LCI) for comparison of composites. 


\section{Methodology}

The proposed methodology has three steps and combines: a micromechanical model developed to be representative also for NFC [5], the Ashby methodology [6] for the functional comparison of composites in different structural applications, and LCA for the assessment of the environmental impact across a multitude of impact indicators. Figure 1 shows the graphical representation of the proposed framework. The individual modules provide the input needed for the succeeding module. Outputs from the proposed methodology are the environmental impact profiles of the different material scenarios. With this new approach, it is possible to evaluate different materials and applications in a unified framework, not relying on case based comparisons. The methodology allows for a comparative early stage material screening with obvious eco-design application perspectives, or else identifying the application where a selected material can have the lowest environmental impacts.

\subsection{Material properties}

Composite properties depend on the specific properties and mixing ratio of fibre and matrix materials.

To predict the composite properties, we used the micromechanical model developed by Madsen et al [5], which takes into account the effect of the porosity on the final composite properties and allows calculating the mechanical properties and

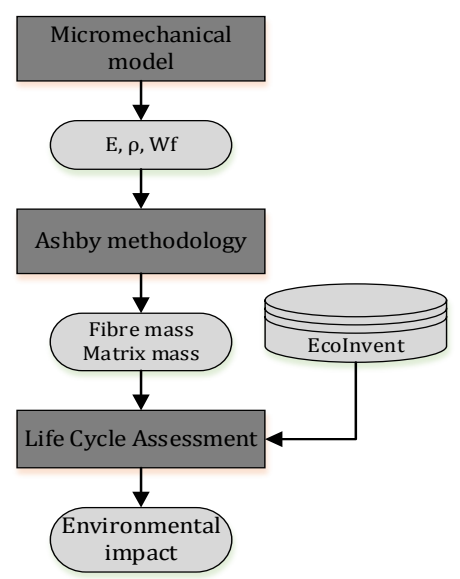

Fig. 1 The proposed method ( $E$ is the elastic modulus, $\rho$ the density and Wf the fibre weight fraction of the composite)

the density of the composite as a function of the fibre weight fraction.

Porosity is known to affect the properties of the composite and for synthetic fibres (e.g. glass fibres); a large pool of knowledge has been accumulated on how to diminish the porosity part when

producing composites [7]. For NFs, the porosity is related to a number of known factors including the luminal cavities in the plant fibre, the heterogeneous shape of the fibre and the surface chemistry between fibre and matrix [8].

The model predicts two cases of composite volumetric interactions, at low and high fibre fraction. Those are separated by a transition fibre weight fraction, at which the combination of a high fibre volume fraction, low porosity and a high composite density is optimal, resulting in the highest mechanical properties achievable. Detailed explanation of the method is available from [5].

Once the fibre and matrix parameters and the fibre weight fraction have been decided, the model calculates density and elastic modulus of the resulting composite. The model can also be used to calculate the optimal fibre weight fraction ( $\mathrm{Wf}_{\text {trans }}$ ) which under the specific operating conditions results in the best achievable mechanical properties.

\subsection{Type of structural application}

The second module evaluates the material performance in different applications using the Ashby methodology [6]. This methodology is widely employed for material selection, allowing for calculation of the masses of alternative materials needed to achieve equal mechanical performances. 
The Ashby methodology calculates a performance index (Ashby's Index) for each considered application, based on the material properties and the design constraints. The mass of a material needed to fulfil the design requirements will be proportional to the calculated Ashby index.

Inputs for the Ashby index calculation, are the mechanical properties and density of the composite obtained from the micromechanical model. Outputs of this module are the Ashby indices representative for the different applications considered. Subsequently, when the mass of the reference scenario has been defined, it is possible to estimate the mass of material needed to fulfil the same design requirements.

\subsection{Environmental performance/impact}

LCA is used to assess the environmental performance of the resulting composite material. LCA is the most generally accepted method for quantification of the environmental impacts related to a product or a system [9]. It estimates the potential impacts arising during the whole life cycle of a product, from the extraction of the resources (cradle) to the final disposal of the product (grave), considering a broad range of environmental impact categories, and is hence not only focusing on climate change. LCA is an iterative process composed of 4 phases:

-Goal and scope definition

-Inventory data collection

-Impact assessment

-interpretation

Input for the LCA module are the material amounts required for each composite scenario which are used to scale the inventory to represent the specific material scenario.

\section{Application of the method}

The presented method was applied in a comparison of the environmental performance of glass fibre reinforced plastic composite (GFRP) and flax fibre reinforced composites (FFRP).

3.1. Goal and scope definition

The purpose of the study is to compare the use of FFRP and GFRP in different structural applications and at different fibre weight fractions. The fibre materials evaluated in this study are: flax fibres, one of the most commonly used natural fibres on the market [10], and glass fibres, representing the dominating conventional fibrous reinforcement solution. The fibres are combined with a thermoplastic polypropylene matrix. Polypropylene is the most frequently used thermoplastic reinforcement, holding almost $70 \%$ of the European market for thermoplastic matrix materials [11]. The material properties used as input for the micromechanical model are presented in table 1. Composite structures are produced via thermoforming processes. The focus of the study is on indoor furniture applications, where stiffness is the dominant design constraint, and UV light and/or high moisture exposure [12] are unlikely to compromise the durability of the composite.

\subsection{Functional unit}

Following the ILCD guidelines for LCA, a comparison of materials can only be conducted when the same function or service is provided [13]. The functional unit in this study is: "To provide the equivalent mechanical stiffness performance of $1 \mathrm{~kg}$ of GFC in different mechanical applications".

\subsection{System boundaries}

The boundaries of our study go from cradle to grave. The geographical boundaries are set to Europe. Cultivation and fibre production steps for flax fibres are taken from [14], while other inventory data are taken from the Ecolnvent 2.2 database [16]. Transportation has been excluded due to the low contribution to the overall environmental performance [15]. The composite structures are produced via thermoforming processes. Incineration with energy recovery is assumed as the most likely and most representative disposal scenario. 


\subsection{Impact assessment method}

The GaBi 6 [17] software was used to perform the product system modelling. The applied impact assessment methodology is ReCiPe Midpoint H [18]. ReCiPe offers assessment at different aggregation levels of the environmental performance. Midpoint level results represent specific environmental problems whereas the endpoint and single score results are aggregated into a few or one single score(s). ReCiPe was chosen since it is one of the most recent and complete impact assessment methodologies available. In this study, only midpoint results calculated using the Hierarchical perspective are compared. Normalization has been performed using the European reference set [18].

\begin{tabular}{llll}
\multicolumn{4}{l}{ Table 1 Input parameter for the micromechanical model } \\
\hline Parameter & Unit & FFRP & GFRP \\
Fibre elastic modulus & $\mathrm{GPa}$ & 50 & 72 \\
$\begin{array}{l}\text { Matrix elastic modulus } \\
\text { Fibre density }\end{array}$ & $\mathrm{GPa}$ & 2 & 2 \\
$\begin{array}{l}\text { Matrix density } \\
\text { F/cm }\end{array}$ & 1.5 & 2.7 \\
$\begin{array}{l}\text { Fibre porosity } \\
\text { constant }\end{array}$ & $\mathrm{g} / \mathrm{cm}^{3}$ & 0.9 & 0.9 \\
$\begin{array}{l}\text { Maximum fibre } \\
\text { volume fraction }\end{array}$ & 0.1 & 0 \\
$\begin{array}{l}\text { Fibre } \\
\text { factor orientation }\end{array}$ & {$[-]$} & 0.35 & 0.50 \\
\hline
\end{tabular}

\section{Results}

\subsection{Testing different application}

Figure 2 shows the normalized midpoint results of the substitution of GFRP and FFRP in three structural applications (rod in tension, beam in bending, and panel in bending), all of them with stiffness as main design constraint. Only relevant impact categories (IC), contributing more than $1 \%$ to the total impact score, after the midpoint normalization step, are presented (13 of 17 available in ReCiPe). In each application, $1 \mathrm{~kg}$ of GFRP is set as reference. The environmental impact profiles of the alternative scenarios are related to the amount of FFRP needed to fulfil the same stiffness requirements (i.e. mechanical performance) as the reference. Both GFRP and FFRP properties are calculated at the $\mathrm{Wf}_{\text {trans }}$ (i.e. where both composites have the best mechanical properties).

As visible from Figure 2 the FFRP shows better environmental performance than GFRP in beam and panel applications for all impact categories except marine eutrophication (due to leaching of the fertilizer used in the agricultural cultivation of flax). Among the FFRP applications, the panel application performs best, while the application of FFRP in rods has poorer performance than GFRP in some ICs. 
Figure 2 Midpoint normalized results for GFRP and FFRP in different structural applications. GFRP is used as a reference scenario (black column). While the three other columns show the impact of the FFRP substituting the GFRP in different applications.

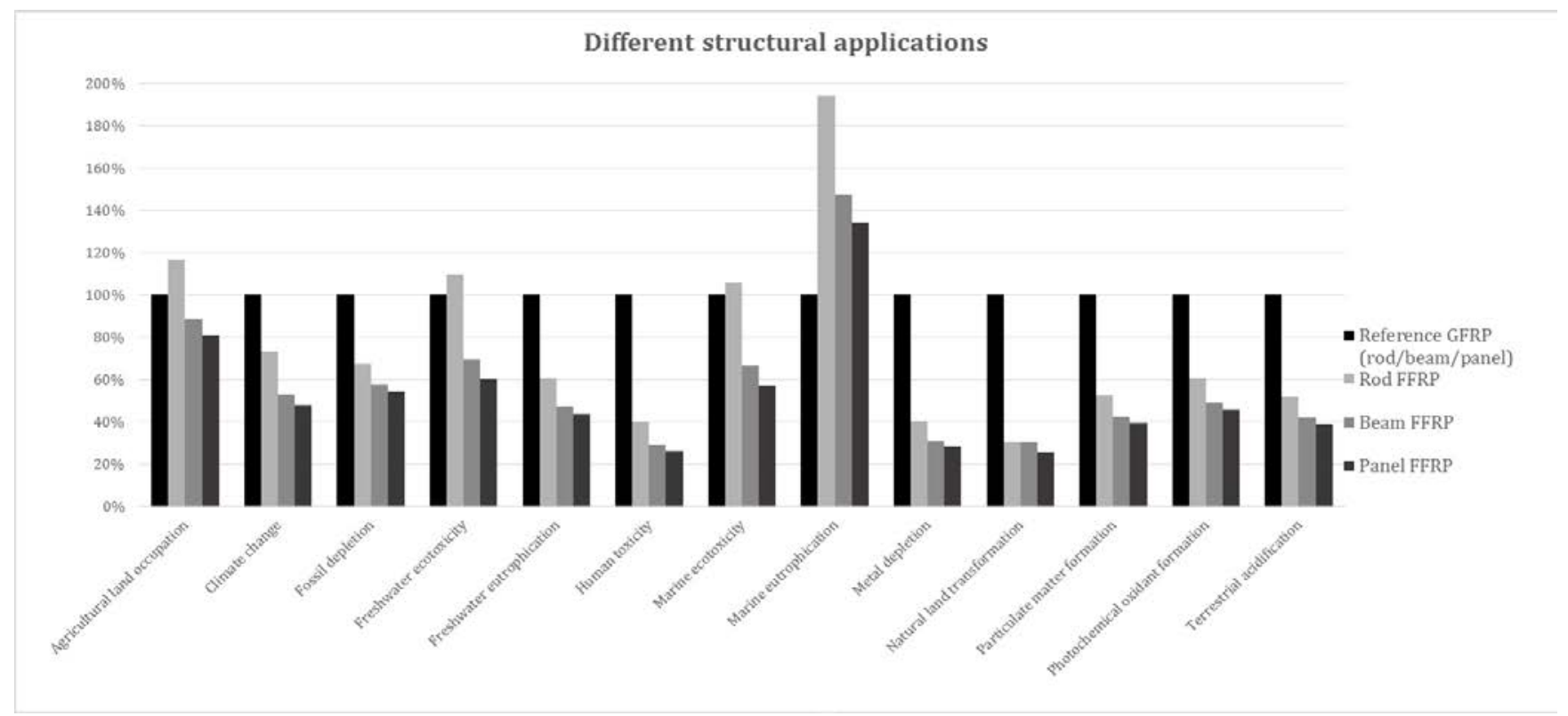

\subsection{Testing the optimal fibre weight fraction}

In addition to the comparison based on mechanical service, we tested the environmental performance of the FFRP as a function of the fibre weight fraction $\left(\mathrm{W}_{\mathrm{f}}\right)$, analysing the substitution of $1 \mathrm{~kg}$ of GFRP in a rod application with FFRP at different fibre weight fractions in the composite (from $10 \%$ to $80 \%$ ). The normalized LCA results follow three general trends:

1) Inverted bell curve with minimum at $W_{\text {ftrans }}$ (for 9 out of 13 ICs)

2) Decreased impact with increasing $W_{f}$ (for 2 out of 13 ICs)

3) Increased impact with increasing $W_{f}$ (for 2 out of 13 ICs)

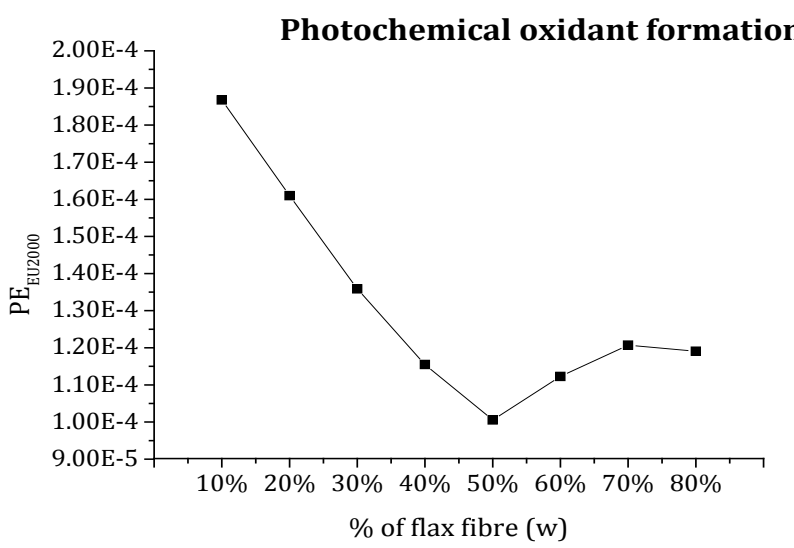

Fig. 3 Normalized results for photochemical oxidant formation as a function of the fibre weight content (Hierarchist perspective, Europe)

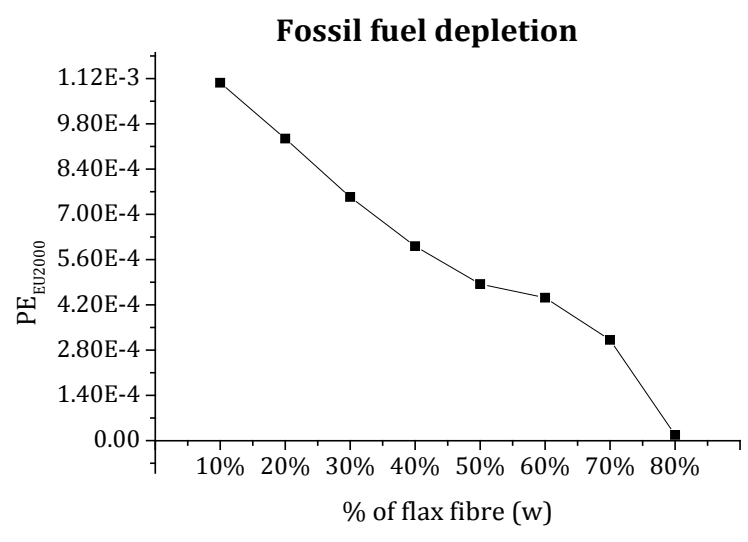

Fig. 4 Normalized results for fossil fuel depletion as a function of the fibre weight content (Hierarchist perspective, Europe)

Figure 3 presents the normalized results for the IC photochemical oxidant formation showing the first trend type, where the lowest environmental impact potential is found where high mechanical performance is achievable (i.e. $\left.W_{f \text { trans }}\right)$. 
Climate change and fossil fuel depletion exhibit a continuously decreasing performance trend when increasing the weight fraction of NF as shown for fossil fuel depletion in Figure 4.

The impact categories marine eutrophication and metal depletion exhibit a poorer environmental performance with increasing fibre weight fraction. Figure 5 shows the results for marine eutrophication.

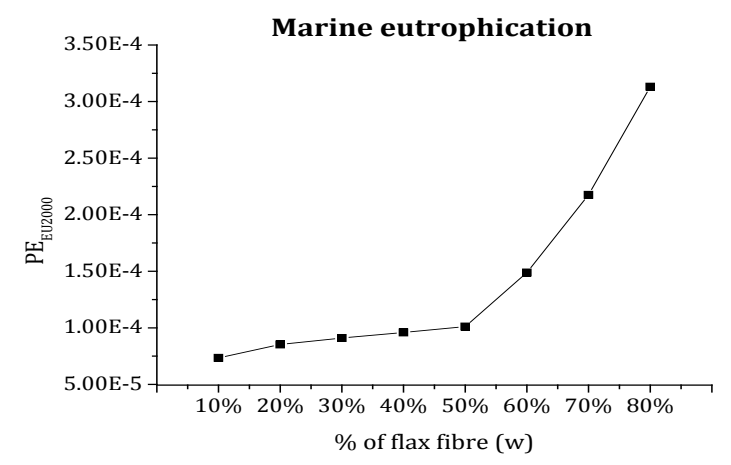

Fig. 5 Normalized results for marine eutrophication as a function of the fibre weight content (Hierarchist perspective, Europe)

\section{Discussion}

\subsection{Testing different application}

Results in Figure 2 show that while substitution of GFRP with FFRP is generally preferable from an environmental impact perspective, panel application is the best choice. FFRP has both a lower density and a lower elastic modulus than GFRP. For a rod in tension, the mass needed to fulfil a certain mechanical requirement is proportional to $E / \rho$, for a beam in bending it is, while for a panel in bending it is [6]. Hence, the highest weight reduction, which implies the best environmental performance, is achieved for panel application due to the lower $\sqrt{E} / \mathrm{\rho}$ dependence of the Ashby $\sqrt[3]{E} / \mathrm{\rho}$ index on the elastic modulus.

For few ICs FFRP exhibits higher impact. Those impacts are mainly originating from the agricultural stage. Especially for marine eutrophication, the high impact is due to leaching of nutrients due to the fertilizer use. Other natural fibres, which require less fertilizer and pesticide applications (e.g. hemp.), could reduce those impacts [19]. Impact savings would potentially be higher if the materials were used in dynamic applications (e.g. car) where the lower mass would result in considerable fuel savings in the use stage [20].

\subsection{Testing different fibre weight fraction}

For most ICs, the best environmental performance is achieved for the composition where the fibre and matrix combination provides the strongest mechanical properties (i.e. at $\mathrm{Wf}_{\text {trans }}$ ) as illustrated in Figure 3.

For the ICs climate change and fossil fuel depletion, the impact potential decreases even when increasing $W_{f}$ beyond this point because these impact potentials are dominated by the polymeric matrix, since PP is made from fossil resources.

For the ICs marine eutrophication and metal depletion, the impact potentials increase continuously with $W_{f}$ because the main contributions to these two ICs come from the cultivation of flax. Similar trends are observed for beam and panel applications across the different impact categories.

\section{Conclusion}

The proposed comparison model supports an environmental assessment of NFC that caters to the needs of Life Cycle Engineering by taking into account both the specific mechanical properties of the constituent materials, the application type and the environmental impact of the matrix and fibre materials throughout the life cycle.

The method may be used in an eco-design perspective supporting the material selection phase and its modular structure allows easy update when better options evolve for any of the modules.

The results show that replacement of glass fibres with flax fibres show a general reduction of the environmental impact regardless the type of application. They also demonstrate that the highest impact reduction potential, 
Corona A, Madsen B, Hauschild MZ, Birkved M (2016) Natural fibre selection for composite Eco-design. CIRP Ann - Manuf

Technol 65:13-16. doi: 10.1016/j.cirp.2016.04.032

considering not only climate change, is found when the combination of fibre and matrix is optimal, not when the natural material content is maximized.

\section{References}

[1] Duflou, J.R., Yelin, D., Van Acker, K., Dewulf, W., 2014, Comparative impact assessment for flax fibre versus conventional glass fibre reinforced composites: Are bio-based reinforcement materials the way to go?, CIRP Annals Manufacturing Technology, 63/1:45-48

[2] Dicker, M.P.M., Duckworth, P.F., Baker, A.B., Francois, G., Hazzard, M.K., Weaver, P.M., 2014, Green composites: A review of material attributes and complementary applications, Composites Part A: Applied Science and Manufacturing, 56:280-289.

[3] Dissanayake, N.P.J., Summerscales, J., Grove, S.M., Singh, M.M., 2009,. Life Cycle Impact Assessment of Flax Fibre for the Reinforcement of Composites, Journal of Biobased Materials and Bioenergy, 3, 245-248.

[4] Le Duigou, A., Baley, C., 2014, Coupled micromechanical analysis and life cycle assessment as an integrated tool for natural fibre composites development, Journal of Cleaner Production, 83, 61-69

[5] Madsen, B., Thygesen, A., Lilholt, H., 2007, Plant fibre composites - porosity and volumetric interaction, Composites Science and Technology, 67:1584-1600.

[6] Ashby, M.F., 2011, Materials selection in mechanical design. Fourth edition, Butterworth-Heinemann

[7] Manson, Ê., Wakeman, M.D., Bernet, N., 2000, Composite Processing and Manufacturing - An Overview, Comprehensive Composite Materials. Volume 2, 577-607, Elsevier Science Ltd.

[8] Lilholt, H., Toftegaard, H., Thomsen, B., Schmidt, S., 1999, Natural composites based on cellulosic fibres and polypropylene matrix - Their processing and characterisation, Proceedings of ICCM, 12:9

[9] Finnveden, G., Hauschild, M.Z., Ekvall, T., Guinée, J., Heijungs, R., Hellweg, S., Suh, S., 2009, Recent developments in Life Cycle Assessment, Journal of Environmental Management, 91/1:1-21.

[10] Bos, H.L., 2004, The potential of flax fibres as reinforcement for composite materials, Technische Universiteit Eindhoven.

[11] Carus, M., 2011, Bio-Composites: Technologies, Applications and Markets, 4th International Conference on Sustainable Materials, Polymers and Composites, Birmingham, UK, 6-7, July 2011

[12] Mohammed, L., Ansari, M.N.M., Pua, G., Jawaid, M., Islam, M.S., 2015, A Review on Natural Fiber Reinforced Polymer Composite and Its Applications, International Journal of Polymer Science,2015:1-15

[13] European Commission - JRC-IES, 2010. International Reference Life Cycle Data System (ILCD) Handbook General guide for Life Cycle Assessment - Detailed guidance. EUR 24708 EN. Luxembourg,

[14] Labouze, E., Le Guern, Y., Petiot, C., 2007, Analyse du Cycle de Vie comparée d'une chemise en lin et d'une chemise en coton, Bio Intelligence Service, 33:1-117

[15] Corona, A., Markussen, C.M., Birkved, M., Madsen, B., 2015, Comparative Environmental Sustainability Assessment of Bio-Based Fibre Reinforcement Materials for Wind Turbine Blades, Wind Engineering, 39/1:53-64.

[16] Frischknecht, R., Jungbluth, N., Althaus, H.J., Doka, G., Dones, R., Heck, T., Spielmann, M., 2005, The ecoinvent database: Overview and methodological framework, International Journal of Life Cycle Assessment, 10/1:3-9

[17] PE GaBi 6, 2011, PE International - Software-System and Databases for Life Cycle Engineering, Stuttgart, Germany

[18] M. Goedkoop, M., Heijungs, R., Huijbregts, A. De schryver, J. Struijs, R. Van Zelm, 2008, ReCiPe: a life cycle impact assessment method which comprises harmonised category indicators at the midpoint and the endpoint level. first edition (revised)

[19] González-García, S., Hospido, A., Feijoo, G., Moreira, M.T., 2010, Life cycle assessment of raw materials for nonwood pulp mills: Hemp and flax, Resources, Conservation and Recycling, 54:923-930

[20] Duflou, J.R., De Moor, J., Verpoest, I., Dewulf, W., 2009, Environmental impact analysis of composite use in car manufacturing, CIRP Annals - Manufacturing Technology, 58/1:9-12. 